\title{
Benin: Diríjase a los hombres para aumentar el uso de los servicios de salud
}

Frontiers in Reproductive Health

Follow this and additional works at: https://knowledgecommons.popcouncil.org/departments_sbsr-rh

Part of the Community-Based Research Commons, Demography, Population, and Ecology Commons, Family, Life Course, and Society Commons, International Public Health Commons, and the Medicine and Health Commons How does access to this work benefit you? Let us know!

\section{Recommended Citation}

"Benin: Diríjase a los hombres para aumentar el uso de los servicios de salud," Resúmenes de Investigación Operativa. Ciudad de México: Population Council, 2001. 


\section{Benin \\ Acceso}

\section{Resumen de $1 \mathrm{O} 13$}

\title{
Diríjase a los hombres para aumentar el uso de los servicios de salud
}

\begin{abstract}
En las áreas rurales de Benin, los hombres controlan los recursos del hogar y toman la mayoría de las decisiones sobre la maternidad y el uso de los servicios de salud. Para mejorar la salud materna e infantil, los programas deberían educar a los miembros de la comunidad acerca de la necesidad de invertir en el cuidado de la salud y de buscar tratamiento oportuno para las enfermedades. Asimismo, los programas de salud reproductiva deberían educar a los hombres respecto a la planificación familiar y atender las preocupaciones de las mujeres sobre los efectos secundarios de los anticonceptivos.
\end{abstract}

\section{Antecedentes}

Después del inicio de las reformas del sector salud en 1994, el gobierno de Benin creó el Proyecto de Salud Familiar Integral, conocido localmente como PROSAF. Este proyecto opera en la región de Borgou, bajo el patrocinio de la Agencia de los Estados Unidos para el Desarrollo Internacional. Dicha región es en su mayoría rural y en ella se observan los problemas de salud más severos del país.

Los gerentes de PROSAF deseaban entender por qué la gente no estaba utilizando los servicios a pesar de tener una salud deficiente, por lo que solicitaron al Centro Africano de Investigación en Población y Salud (APHRC, por sus siglas en inglés) que estudiara de qué manera los hogares y las comunidades de Borgou toman sus decisiones sobre el cuidado de la salud. Con el apoyo del Population Council, el APHRC realizó un estudio de mayo a diciembre de 2000, con el fin de identificar los factores socioculturales que pudieran impedir el acceso a los servicios de salud en la región y presentar recomendaciones para superar esos obstáculos.

Como parte de este estudio cualitativo, los investigadores realizaron 108 entrevistas a profundidad y 36 sesiones de discusión con grupos focales en cinco distritos de Borgou. El estudio utilizó una muestra representativa de la población de la región, estratificada por grupo étnico, género y edad (15-24 años, 25-49 y 50 en adelante). En cada distrito, los investigadores entrevistaron a un funcionario médico, una enfermera, una partera, un curandero y a un agente comunitario.

\section{Resultados}

Tres factores principales que afectan el acceso y uso de los servicios de salud y de planificación familiar son:

$\diamond$ En la asignación de los recursos del hogar, las prioridades son la agricultura, la vivienda y las ceremonias, como funerales y bodas. Los pagos por servicios de salud dependen de la disponibilidad de fondos en el momento de la enfermedad.

$\diamond$ Los hombres toman decisiones unilaterales en cuanto a la asignación de los recursos para el hogar y la atención de la salud.

"Mi dinero y yo estamos bajo el control de mi esposo."

(Mujer casada de 48 años)

$\diamond$ La población prefiere servicios alternativos de atención a la salud, y recurre principalmente a 
curanderos o a la automedicación, por su bajo costo. La percepción sobre la causa de la enfermedad — tal como la idea de que usar amuletos puede curar fiebres o prevenir infecciones, las de transmisión sexual inclusive- repercute también en el tipo de atención que se busca. El uso de la medicina moderna suele ser la última opción y se recurre a ella únicamente cuando los síntomas son avanzados.

- Cuando la población acude a centros modernos de salud, la calidad de la atención se vuelve la preocupación más importante. Los usuarios pagan cuotas más elevadas y se desplazan a distancias mayores para recibir una mejor atención. Entre las razones que los miembros de la comunidad citaron para confiar en fuentes alternativas de atención a la salud, están la escasez de suministros y medicamentos, así como el ausentismo, la falta de capacitación, el trato inadecuado a pacientes y el mercado negro de medicamentos por parte de los proveedores.

Gran parte de la población ha oído hablar de los métodos anticonceptivos modernos, en particular de los inyectables, las pastillas y el DIU. Tanto hombres como mujeres vieron en la PF una forma de espaciar los nacimientos con beneficios tales como descanso para la madre, mejor atención para los niños y menos tensiones económicas para la familia. Además, la consideraron como sustituto de la abstinencia sexual, que era el método tradicional de espaciar nacimientos. Los hombres que participaron en el estudio entendieron que los condones pueden evitar el embarazo y el VIH/SIDA, aunque más bien los utilizan para tener relaciones sexuales extramaritales.

Pocas mujeres usan anticoncepción moderna debido a su preocupación por los efectos secundarios. La desaprobación de los esposos también limita su uso, ya que son los hombres los que toman decisiones relacionadas con la fecundidad. Muchas mujeres piensan que los proveedores requieren el consentimiento de sus esposos para el uso de anticonceptivos; sin embargo, algunas los obtienen en secreto.

Se habla poco sobre PF, tanto entre esposos y esposas como entre padres e hijos. Los adolescentes dijeron que uno de los principales factores de esta falta de comunicación es la vergüenza, ya que tanto ellos como los adultos asocian el uso de PF con promiscuidad e infidelidad. Las mujeres por su parte dijeron que hablar de PF con sus esposos podría generar desacuerdos familiares, violencia o divorcio. Expresaron que existe una necesidad urgente de proporcionar información sobre PF a los esposos.

\section{Implicaciones normativas}

Los programas que buscan aumentar el uso de servicios modernos de salud, incluyendo los de PF, deben involucrar a los hombres. El uso de agentes comunitarios debidamente capacitados podría ser una forma efectiva de cambiar las actitudes de los hombres hacia la PF.

Los programas comunitarios deberían despertar mayor conciencia sobre la necesidad de solicitar tratamiento para las enfermedades tan pronto como se presenten. Los precios de los medicamentos deberían estandarizarse, darse a conocer a la población y exhibirse en todos los centros de salud.

Se debería capacitar a los prestadores para que mejoren o actualicen sus habilidades, en particular las de sus relaciones interpersonales; y a los supervisores para mejorar la supervisión del personal, evitar el ausentismo y fortalecer el manejo de medicamentos.

Mayo 2001

Ngom, Pierre et al. 2000. Intra-Household Decision-Making on Health and Resource Allocation in the Borgou, Bénin: Final Report. Para obtener más información escriba o llame a: African Population and Health Research Center, P.O. Box 17643, Nairobi, Kenia. Tel.: 254-2-713 480; Fax: 254-2-713 479; E-mail: aphrc@ popcouncil.or.ke .

Este proyecto se llevó a cabo con el apoyo de la Agencia de los Estados Unidos para el Desarrollo Internacional (USAID), de conformidad con el Acuerdo de Cooperación número HRN-A-00-98-00012-00. 